\title{
Correction to: Safe injection awareness and practices among nursing staff in an Egyptian and a Saudi hospital
}

Manal M. Anwar ${ }^{1 *}$, Alshimaa M. Mohamed Lotfy ${ }^{1}$ and Afaf A. Alrashidy ${ }^{2}$

Correction to: J Egypt Public Health Assoc https://doi.org/10.1186/s42506-019-0018-5

Following publication of the original article [1], we have been notified that one of the authors' given names is not reflected correctly.

Author name now is Alshimaa A. Mohamed Lotfy, it should be Alshimaa M. Mohamed Lotfy.

\section{Author details}

'Department of Public Health and Community Medicine, Faculty of

Medicine, Beni-Suef University, Beni Suef, Egypt. ${ }^{2}$ Ministry of Health, Al

Qassim Region, Kingdom of Saudi Arabia.

Published online: 25 February 2020

\section{Reference}

1. Anwar, et al. Safe injection awareness and practices among nursing staff in

an Egyptian and a Saudi hospital. J Egypt Public Health Assoc. 2019;94:21.

https://doi.org/10.1186/s42506-019-0018-5

\footnotetext{
*Correspondence: M_anwarabdo@yahoo.com; manal.abdo@med.bsu.edu.eg The original article can be found online at https://doi.org/10.1186/s42506019-0018-5

'Department of Public Health and Community Medicine, Faculty of

Medicine, Beni-Suef University, Beni Suef, Egypt

Full list of author information is available at the end of the article
} 